\title{
Irrelevant Cultural Influences on Belief
}

\author{
Robin McKenna
}

University of Liverpool

rbnmckenna@gmail.com

r.j.mckenna@liverpool.ac.uk

\begin{abstract}
Recent work in psychology on 'cultural cognition' suggests that our cultural background drives our attitudes towards a range of politically contentious issues in science such as global warming. This work is part of a more general attempt to investigate the ways in which our wants, wishes and desires impact on our assessments of information, events and theories. Put crudely, the idea is that we conform our assessments of the evidence for and against scientific theories with clear political relevance to our pre-existing political beliefs and convictions. In this paper I explore the epistemological consequences of cultural cognition. What does it mean for the rationality of our beliefs about issues such as global warming? I argue for an unsettling conclusion. Not only are those on the 'political right' who reject the scientific consensus on issues like global warming unjustified in doing so, some of those on the 'political left' who accept the consensus are also unjustified in doing so. I finish by addressing the practical implications of my conclusions.
\end{abstract}

\section{Introductory Remarks}

It is a common observation that our views about certain scientific topics 'track' our political affiliations and broader cultural backgrounds. If you are told Daisy is a "liberal Democrat" and lives in New York, you will expect Daisy to accept that global warming ${ }^{2}$ is happening, and human activity is causing it; if you are told Rachael is a 'conservative Republican' and lives in Wyoming, you will expect Rachael to be more suspicious of the impact of human activity on global warming, and of the existence of global warming itself. ${ }^{3}$ These expectations are reasonable when you consider the statistical data. A 2017 report from the Yale Program on Climate Change Communication gives us this breakdown of the variation in beliefs about global warming across the political divide:

- $71 \%$ of registered voters in the US think global warming is happening. But beliefs about whether it is happening vary widely across the political spectrum: 97\% of liberal Democrats think global warming is happening, as opposed to only $42 \%$ of conservative Republicans. 
There is also a divide between self-described 'moderates': $85 \%$ of moderate Democrats think it is happening, as opposed to $65 \%$ of moderate Republicans.

- $56 \%$ of registered voters think global warming is largely caused by human activities. But, again, beliefs vary widely across the political spectrum: $87 \%$ of liberal Democrats think global warming is largely caused by human activities, as opposed to $30 \%$ of conservative Republicans. Again, there is also a divide between moderates: $62 \%$ of moderate Democrats think it is largely caused by human activities, as opposed to $45 \%$ of moderate Republicans. ${ }^{4}$

There are several ways in which one might try to explain this variation in beliefs. Some hold that liberals are just smarter than conservatives. ${ }^{5}$ More guardedly, others hold that conservatives tend to have certain personality traits (e.g. closed-mindedness) that might explain why they are resistant to evidence that goes against their deeply held political convictions. ${ }^{6}$ What these explanations have in common is that they postulate an epistemological asymmetry between liberal and conservative attitudes about scientific issues such as global warming. Liberals tend to appreciate the force of the scientific evidence and tend to accept that global warming is happening (and humans are the cause of it) on the basis of this evidence, whereas conservatives tend to reject that evidence, and so tend to deny that global warming is happening. Liberal Democrats like Daisy are justified in their belief that global warming is happening; conservative Republicans like Rachael are unjustified in their denial that global warming is happening.

In this paper I focus on work in psychology and political science on cultural cognition. ${ }^{7}$ Dan Kahan and his collaborators present evidence that both liberals and conservatives form beliefs about politically contentious scientific issues (such as global warming) in ways that reflect their political views and broader cultural identities. I want to explore the epistemological consequences of cultural cognition. I argue that, because cultural cognition is not a reliable way of forming beliefs about politically contentious scientific issues, if you learn that your beliefs about these issues were formed via cultural cognition, and that cultural cognition is not a reliable way of forming beliefs about such issues, then you should downgrade your confidence in (or even abandon) these beliefs. I claim that this goes both for conservative Republicans like Rachael and liberal democrats like Daisy. This conclusion, if right, is unsettling. It is no surprise to learn that conservative Republicans are unjustified in rejecting the evidence for global warming. It would be surprising to learn that many liberal Democrats who, like Daisy, accept the evidence, are not necessarily justified in doing so. 
Here is the plan. $\$ 2$ introduces and reviews the evidence for cultural cognition. $\$ 3$ argues for my unsettling conclusion. $\$ 4-5$ address two objections to this argument. $\$ 6$ addresses the practical implications of my conclusions.

\section{Cultural Cognition: Some Background}

Our wants, wishes, desires and preferences impact on our cognitive processes. In the psychology literature, work on motivated reasoning looks at the extent and nature of this impact. This work documents the myriad ways in which we tend to (unconsciously) conform our assessments of information, events and theories to goals other than the goal of basing our judgements on the best available information. ${ }^{8}$ For example:

- We tend to take responsibility for our successes ('I'm good at this') and deny responsibility for our failures ('I was unlucky'). ${ }^{9}$

- We tend to give more credence to information that confirms our perception of ourselves as kind, competent and healthy than to information that challenges these perceptions. ${ }^{10}$

- We describe scientific research that confirms our views on complex social issues (e.g. capital punishment) as better conducted, and its conclusions as more valid, than research that clashes with our strongly held views. ${ }^{11}$

Manifestations of motivated reasoning can be distinguished according to the goals or motivations they serve. Much of the literature focuses on the goal of maintaining a positive self-conception. ${ }^{12}$ But other work focuses on politically motivated reasoning. ${ }^{13}$

When we engage in politically motivated reasoning, we subject information that conflicts with (or that we perceive to conflict with) our political convictions to extensive scrutiny, trying to find flaws and reasons to dismiss. But, when we receive information that supports (or that we perceive to support) our political convictions, we accept it uncritically. For instance, Milton Taber and Charles Lodge conducted a study in which subjects from across the political spectrum were asked to assess the strength of arguments for and against gun control and affirmative action policies. ${ }^{14}$ They found that their assessments were influenced by their political beliefs about these topics. Subjects were given the same set of arguments, but evaluated the arguments that supported their pre-existing views as stronger than the arguments that challenged those views.

Taber and Lodge hypothesise that this is the result of two biases. First, we tend to spend more time finding flaws with arguments that challenge our deeply-held political convictions than we do 
on finding flaws with arguments that support these convictions. Second, when we are free to choose which information to expose ourselves to, we tend to seek out arguments that will confirm our deeply-held political convictions rather than arguments that will challenge these convictions. These biases lead to attitude polarisation: our attitudes about 'hot' political topics like gun control and affirmative action policies become more extreme over time. It is crucial to note that these biases are more pronounced in those with higher levels of political sophistication. Thus, these results are not due to ignorance of the relevant political issues. This has important implications for the question of what can be done to ameliorate the impact of politically motivated reasoning on democratic institutions. ${ }^{15}$

How widespread is politically motivated reasoning? In their work Kahan and his collaborators look at the following topics, among others:

- Attitudes about global warming.

- Attitudes about the safety of 'burying' nuclear waste underground.

- Attitudes about the efficacy of 'concealed carry' laws.

Kahan, Jenkins-Smith and Braman found that those on the 'political left' tend to think there is scientific consensus that humans are causing global warming whereas those on the 'political right' tend to think that scientists are divided. ${ }^{16}$ But those on the left tend to deny that there is scientific consensus that there are safe methods of disposing of nuclear waste. While those on the right also tend to deny this, they are significantly less sceptical than those on the left. Finally, those on the left tend to think that most scientists agree that concealed carry laws are not effective, whereas those on the right tend to think that most scientists agree that concealed carry laws are effective.

What does this tell us? First, these findings suggest that the reason why there is such widespread disagreement among laypersons about issues like global warming and the safety of burying nuclear waste is not because laypersons are unwilling to defer to expert opinion and consensus. Rather, the reason is that there is widespread disagreement among laypersons about what the expert consensus actually is.

Second, this puts both those on the right and those on the left at odds with expert scientific opinion, at least as it is represented in 'expert consensus reports' produced by the US National Academy of Sciences (NAS). The NAS has issued reports detailing scientific consensus that humans are causing global warming ${ }^{17}$ and that there are safe methods of burying nuclear waste. ${ }^{18}$ 
The NAS has also issued a report that the evidence doesn't permit forming a conclusion on the efficacy of concealed carry laws. ${ }^{19}$ These findings therefore suggest that those on the right are out of step with the scientific consensus when it comes to global warming. But they also suggest that those on the left are out of step with the scientific consensus when it comes to the safety of burying nuclear waste. And both those on the right and those on the left are overly optimistic about what the evidence shows about the efficacy of concealed carry laws, albeit in different ways. Both overestimate the extent to which the evidence supports their favoured position.

Finally, all this provides support for the 'cultural cognition thesis'. Laypersons' political convictions impact on their beliefs about the scientific consensus on global warming and other 'hot' political issues. They tend to overestimate the level of scientific support for positions that conform (or that they perceive to conform) with their political convictions. Further, they tend to underestimate the level of scientific support for positions that don't conform (or that they perceive to not conform) with their political convictions. This goes for both sides of the political spectrum, not just those on the right. Those on the right (radically) underestimate the level of scientific support for (humancaused) global warming, but those on the left underestimate the level of scientific support for the safety of burying nuclear waste. One might argue that cultural cognition is more pronounced amongst those on the right. This may be so, but that hardly shows it doesn't also affect those on the left.

This completes my overview of the evidence for cultural cognition. The take-home message is that there is compelling evidence that we tend to conform our assessment of information about politically relevant scientific issues to our political beliefs. This tendency holds across the political spectrum, although it is arguably more pronounced amongst those on the right. I now turn to the epistemological consequences of this work.

\section{Epistemological Consequences of Cultural Cognition}

$\$ 2$ presented evidence for the cultural cognition thesis: our political convictions impact on our beliefs about scientific issues, like global warming, that are clearly relevant to public policy and have acquired widely recognised social meanings. This section explores the epistemological consequences of cultural cognition. I will argue that, if you learn that your beliefs about these issues were formed via cultural cognition, and that cultural cognition is not a reliable way of forming beliefs about such issues, then you should downgrade your confidence in (or even abandon) these beliefs. 
Here is my argument:

1. Many of us form beliefs about scientific topics with a broader political relevance through cultural cognition.

2. Cultural cognition is not a reliable way of forming beliefs about scientific topics with a broader political relevance.

3. If you learn that your belief that $\mathrm{p}$ was formed through a belief-forming process that is not reliable, you should downgrade your confidence in (or even abandon) your belief that $\mathrm{p}$.

4. If you learn that your beliefs about scientific topics with a broader political relevance were formed through cultural cognition, and that cultural cognition is not a reliable way of forming beliefs about such topics, then you should downgrade your confidence in (or even abandon) your beliefs about these topics.

I will defend each premise in turn. ${ }^{20}$ The empirical evidence surveyed in $\$ 2$ shows that many of us form beliefs about politically contentious scientific topics through cultural cognition. That said, it is worth emphasising two respects in which the influence of cultural cognition is limited. First, there is work suggesting that monetary incentives diminish the impact of motivated reasoning on judgements about political issues. ${ }^{21}$ There is also work suggesting that motivated reasoning is most pronounced when it comes to attitudes and beliefs to which we attach a lot of importance, whether personal, political or cultural ${ }^{22}$, and that experts don't engage in cultural cognition with respect to issues within their domain(s) of expertise. ${ }^{23}$

It is however important to note that there is no evidence that the effects of cultural cognition lessen as scientific comprehension and literacy increase. On the face of it, you would think that public scepticism about what are regarded as settled issues in science (like that human activity is causing global warming) is correlated with public ignorance about the relevant science. Put bluntly, the less you know about climate science, the more likely you are to be sceptical about the existence of global warming, still less that human activity is causing it. But one study found that the opposite is the case, at least for individuals on the political right. ${ }^{24}$ Higher levels of scientific comprehension are associated with a small decrease in the perceived seriousness of the threat posed by global warming. All told, this suggests that many of us assess evidence and form judgements about politically relevant scientific issues in ways that conform with our political convictions, and that knowing more about the relevant issues not only doesn't guard against this tendency but can exacerbate it. 
Turning now to the second premise, the empirical evidence surveyed in $\$ 2$ also shows that cultural cognition is not a reliable way of forming beliefs about politically contentious scientific topics. The evidence suggests that, as a matter of fact, cultural cognition leads those on the (political) left to form true beliefs about some scientific topics (e.g. global warming), but it also leads them to form false beliefs about other scientific topics (e.g. the safety of burying nuclear waste). Cultural cognition leads those on the (political) right to form false beliefs about the scientific consensus on global warming, but it also means they are less out-of-step with the scientific consensus on the safety of burying nuclear waste. These findings therefore suggest that cultural cognition is a way of forming beliefs about scientific topics with a broader political relevance that sometimes gets it right, but other times gets it wrong. While the sample-size is too small to reach a definitive conclusion about the reliability of politically motivated reasoning in the relevant domains (we would need to look at other scientific issues, such as nanotechnology, GMOs, the safety of vaccinations, or of nuclear power in general), it is fair to say that the evidence does not show that it is reliable in this domain, no matter whether it is applied by those on the political left, or those on the political right. ${ }^{25}$

It is also important to note that I am not claiming that cultural cognition is, in general, an unreliable belief-forming process. Whether cultural cognition is a reliable way of forming beliefs about a particular topic or in a certain domain is an empirical question, and can only be answered by looking at the available empirical evidence. The evidence summarised in $\$ 2$ strongly suggests that cultural cognition is not a reliable way of forming beliefs about politically contentious scientific topic. If one wanted to claim that cultural cognition is not reliable in other domains, one would need to gather evidence about those domains.

So far I have argued that the empirical evidence supports the first two premises. I take the third premise to require epistemological rather than empirical support. I will argue that this support can be found in the recent (social) epistemological literature on epistemically irrelevant influences on belief. Many of our beliefs are influenced by factors that have nothing to do with the truth of the relevant beliefs. For instance, you might think that our political beliefs are shaped by our upbringing. ${ }^{26} \mathrm{Or}$, in line with the evidence presented in $₫ 2$, you might think that our beliefs about politically relevant science are shaped by our political beliefs and broader cultural background.

The crucial question in the literature on irrelevant influences is often taken to be whether the recognition that irrelevant influences have shaped a wide range of our beliefs should lead us to doubt, or even abandon, these beliefs. ${ }^{27}$ But, in my view, this is not the crucial question. I am happy 
to grant that the recognition that irrelevant influences have shaped a wide range of our beliefs need not occasion any sort of sceptical worry. But the reason why it need not occasion any sort of sceptical worry is because it need not be accompanied by the recognition that the relevant beliefs are likely mistaken because of the irrelevant influences that have shaped them. What if I not only recognised that my political beliefs have been shaped by my upbringing but also that my political beliefs are likely to be mistaken because of this? This surely would occasion a sceptical worry about my political beliefs: their causal origins mean they are likely to be mistaken! The underlying principle here is identified in an insightful recent paper by Katia Vavova:

Good Independent Reason Principle (GIRP): To the extent that you have good independent ${ }^{28}$ reason to think that you are mistaken with respect to $\mathrm{p}$, you must revise your confidence in $\mathrm{p}$ accordingly_insofar as you can. ${ }^{29}$

Vavova's point is that, while the mere recognition that your beliefs have been influenced by irrelevant factors need not lead you to revise your confidence- it need not give you any reason to think the beliefs are mistaken - the recognition that your beliefs are likely to be mistaken because of this should lead you to revise your confidence. This is because, in general, you should revise your beliefs when you have good reason to think they are mistaken. One way in which you can get good reason to think your beliefs are mistaken is by learning that they were produced by a beliefforming process that is not reliable. So the third premise follows straightforwardly from Vavova's principle. If you learn that a belief was produced by a belief-forming process that is not reliable, then you have good reason to think that you are mistaken with respect to the relevant belief, and you must downgrade your confidence in it.

This completes my defence of the third premise, and so of my argument. In the next two sections I address two objections to my argument, before turning to the practical consequences in the final section.

\section{Independence I}

The first objection is that the third premise is too strong. Imagine you form a belief through a process that is not reliable, yet later come to have independent reasons for thinking that the belief is true. For instance, Catriona formed the belief that Morven is innocent of a terrible crime because of wishful thinking, but she later acquired excellent evidence that Morven is innocent, and now believes on this basis. One might think that Catriona is now justified in believing that Morven is innocent, because she now has independent reasons - that is, reasons that are entirely separate 
from the way in which she initially formed her belief-for thinking that Morven is innocent. If you find this thought compelling, then the third premise must be modified as follows:

$3^{*}$. If you learn that a belief that $\mathrm{p}$ was formed through a belief-forming process that is not reliable, and you lack independent reasons for thinking that $\mathrm{p}$ is true, you should downgrade your confidence in (or even abandon) your belief that $\mathrm{p}$.

One might now object that the experimental work surveyed in $\$ 2$ only shows that many of us formed our beliefs about politically relevant science through cultural cognition. It does not show that many of us also lack independent reason for thinking these beliefs are true. So the empirical evidence doesn't establish what is required to run the argument.

I think this worry is misplaced for two reasons. First, the experimental work doesn't just show that we initially formed beliefs about politically relevant scientific topics through cultural cognition. It also shows that cultural cognition impacts on how we assess new evidence and information pertaining to these topics. Work on cultural cognition doesn't just show that a global warming sceptic (or a sceptic about the safety of nuclear power) initially forms a view about global warming that conforms with their political beliefs and broader cultural background. It also shows that a global warming sceptic assesses new evidence and information about global warming in ways that buttress their existing (sceptical) beliefs.

Second, many (though not all) of us lack any reason to think our beliefs about most scientific topics are true other than that they are supported by what we take the scientific consensus to be. We are therefore forced to fall back on expert opinion. The problem posed by work on cultural cognition is that it shows that our political convictions also impact on our evaluations of who the experts are. Kahan, Jenkins-Smith and Braman present studies which show that subjects' assessments of the level of expertise of (fictional) scientists with seemingly impeccable credentials correlate with how well their positions on topics such as global warming and nuclear waste disposal conform to their political convictions. ${ }^{30}$ Put simply, we regard scientists who take positions with which we disagree as having less expertise than scientists who take positions with which we agree. The problem is therefore that, where we might want laypersons to apply neutral conditions for identifying experts about topics like global warming, laypersons in fact form impressions about who the experts are that are influenced by their prior political beliefs. ${ }^{31}$

If this is right, then we can modify the conclusion of the argument accordingly: 
4*. If you learn (i) that your beliefs about scientific topics with a broader political relevance were formed through cultural cognition (ii) cultural cognition is not a reliable way of forming beliefs about such topics, and you lack independent reasons for thinking these beliefs are true, then you should downgrade your confidence in (or even abandon) your beliefs about these topics.

This modified conclusion still has the same unsettling implications as the original conclusion. While I will work with the original third premise and conclusion for the rest of this paper, the reader should bear in mind that these modified versions are also available.

\section{Independence II}

The second objection also concerns the issue of independence, albeit in a slightly different way. My argument relied on Vavova's principle GIRP, which says that, to the extent that you have good independent reason to think that you are mistaken with respect to $\mathrm{p}$, you must revise your confidence in p accordingly. By 'independent' Vavova means independent of the reasoning and evidence that initially led you to adopt your belief that $\mathrm{p} .{ }^{32}$ So her thought is that, when you are considering whether you are mistaken in having the belief that $\mathrm{p}$ in light of some reason $\mathrm{R}$ for thinking the belief is mistaken, you must bracket the reasoning that initially led you to adopt the belief..$^{33}$ But one might object that this seems to give the wrong result in certain cases. Consider:

MAIL: You have recently moved into a new house. Someone by the name of Vickers used to live in the house, but never told the post office that she moved, so you keep on getting her mail. You know that Vickers doesn't live in the house-she's nowhere to be found! Yet you keep on seeing mail addressed to her, which would be good reason to think that she lived in the house if you didn't know better. ${ }^{34}$

If we bracket the reasoning that initially led you to adopt the belief that Vickers doesn't live in the house, then it seems that you do have good independent reason to think that your belief is mistaken. There's all this mail addressed to her, which is a good reason to think she lives in the house (when you ignore all the evidence that she doesn't). But it doesn't seem like you should revise your confidence at all. So GIRP seems to give the wrong result here.

It may well be that the defender of GIRP can respond to this objection. But for my purposes it will be simpler to modify GIRP. I will say that, if you are considering whether you are mistaken in believing that $\mathrm{p}$ in light of some reason $\mathrm{R}$ for thinking your belief is mistaken, you only need to 
bracket all the reasoning and evidence that is undermined by R. So, for example, when you are considering whether the mail addressed to Vickers is a good reason to think you are mistaken in believing that Vickers doesn't live in the house, you don't need to bracket your abundant evidence that she doesn't live in the house, because the presence of the mail in no way undermines this evidence. In contrast, if you had a good reason to think that you had been hallucinating since you moved into the house (imagine you find out you have been accidentally ingesting large quantities of LSD) then maybe you would need to bracket your evidence that she doesn't live in the house.

This means I endorse the following principle:

Good Undermining Reason Principle (GURP): To the extent that you have a good reason (or good reasons) to think you are mistaken with respect to $\mathrm{p}$ that undermines your initial basis for believing that $\mathrm{p}$ - that is, to the extent that you have a good undermining reason to think you are mistaken with respect to $\mathrm{p}$ - you must revise your confidence in $\mathrm{p}$ accordingly-insofar as you can.

This principle delivers the right result in MAIL: the reason you have to think your belief that Vickers doesn't live in the house is mistaken doesn't undermine your initial basis for believing that Vickers doesn't live in the house. This principle also supports the third premise of my argument. One way in which you can get a good undermining reason to think your beliefs are mistaken is by learning that the way in which you formed your beliefs wasn't reliable. So the third premise also follows straightforwardly from GURP. ${ }^{35}$

I want to finish by addressing one final issue. Both GIRP and GURP contain a proviso that I haven't said anything about yet. They both say that you must revise your confidence insofar as you can. But can we really do this? In the final section I address this question, along with some other broader implications of my argument.

\section{Assessing the Implications}

I have argued for a normative prescription: If you learn that your beliefs about topics like global warming were formed through cultural cognition, and that cultural cognition is not a reliable way of forming beliefs about such topics, then you should downgrade your confidence in these beliefs. This conclusion, if true, is unsettling. It is no surprise to learn that conservative Republicans like Rachael are unjustified in rejecting the evidence for global warming. If I am right, liberal 
Democrats like Daisy, who accept the evidence, may also be unjustified in doing so. But what, exactly, follows from this normative prescription?

We can start with the implications for a subject who falls under this normative prescription. Imagine Daisy and Rachael have both formed their beliefs about scientific topics like climate change through cultural cognition. They are presented with the evidence that this is so, and the evidence that cultural cognition is not reliable when it comes to such topics. ${ }^{36} \mathrm{I}$ say that, as a result, they should at least downgrade their confidence in these beliefs.

One might object that there are good reasons for thinking that they will in fact not do this. We tend to hold on to cherished beliefs and attitudes even in the face of clear and contradictory evidence. ${ }^{37}$ This raises the worry that my normative prescription is idle: neither Daisy nor Rachael will do what I say they should, so what's the point in arguing they should do it? ? $^{38}$

Let me start with a concession. Normative prescriptions can't demand that we do the (psychologically) impossible. Human rationality is "bounded", 39 and prescriptions saying what we should and shouldn't do must obey these bounds. Still, while it is very difficult to persuade subjects to abandon their most cherished beliefs in the face of contradictory evidence, there is ample evidence that it is possible. Humans are more open to being persuaded that their most cherished beliefs are false when they are given reason not to tie their sense of self-worth to these beliefs. ${ }^{40}$ The underlying idea is that evidence against a cherished belief is a serious threat to one's sense of self-worth. One way of responding to this threat is by discarding the evidence. But, if one is given an alternative way of responding to this threat, one may be more willing to take the evidence on board. ${ }^{41}$ So, while it may be difficult to get Daisy and Rachael to downgrade their confidence, there are concrete steps that could be taken to help them do so.

What about the broader implications? I want to highlight two. First, I have argued that, for most laypersons, if they were to become aware of the evidence on cultural cognition and the role it plays in fomenting controversy about topics like climate change, they should downgrade their confidence in their beliefs about these topics, no matter what these beliefs are. This does not mean that I take a scenario in which laypersons all downgrade their confidence in their beliefs about these topics to be optimal! While climate change denial would no longer be an obstacle to collective action in this scenario, a collective suspension of judgement would likely prove to be as much of an obstacle, if not more. 
The moral I want to draw is rather about the nature and causes of the problem of public scepticism about science. ${ }^{42}$ Laypersons'—no matter their scientific literacy—evaluate information pertaining to scientific topics with a broader political relevance in ways that reflect and confirm their existing beliefs. As a result, many laypersons—no matter their scientific literacy—have unjustified beliefs about certain scientific topics. This diagnosis of the nature and causes of the problem of public scepticism conflicts with a familiar narrative. ${ }^{43}$ According to this familiar narrative, the problem is partly that most laypersons are ignorant about science, and partly that some laypersons (those with conservative political beliefs) are 'anti-science'. This narrative gains plausibility from the facts that a lot of laypersons are ignorant and a lot of conservatives are anti-science. But, if I am right, neither ignorance nor conservative ideology is the central cause of the problem.

Second, what steps could be taken to resolve this problem? Cultural cognition poses a problem for what Elizabeth Anderson calls institutional epistemology. ${ }^{44}$ One of the central questions of institutional epistemology is how social institutions (science, democracies) can do a better job of producing and disseminating knowledge. Cultural cognition poses a problem for our systems of knowledge dissemination because it leads individuals to either reject certain scientific results outright (because they clash with their political beliefs), or to accept them merely because they happen to fit with their political beliefs and convictions. Individuals therefore end up with either false or unjustified beliefs about politically relevant science.

Given that cultural cognition is not going to go away, we need to come up with ways of managing the epistemic environment so that the influence of cultural cognition on how individuals think about politically contentious scientific topics is minimised. We can look to the literature on science communication for suggestions as to how this could be done..$^{45}$ One suggestion is to look at how topics like climate change are framed. Discussions of what to do about climate change are often framed in terms of what we can do to reduce carbon emissions. This leads to a situation where (put crudely) conservatives need to choose between the science and their conviction that business should be free from government interference. While carbon emissions reductions are important, we can emphasise other solutions, some of which might be more appealing to conservative sensibilities (e.g. nuclear power). The point is not to advocate for a 'conservative-friendly' set of measures to combat climate change, but rather to better articulate the variety of solutions that are available. 
Another suggestion is to look at who does the communicating. There are conservatives who accept the science on climate change (and liberals who accept that nuclear power can be safe). As discussed above, we generally prefer to receive information from sources we perceive to be similar to us. While this has its downsides-we would rather listen to someone who is like us than someone who isn't, even if we have reason to think they are less likely to be right - it has potential upsides in the present context. If we take steps to ensure that a politically diverse group make the case for action on climate change (or for the safety of nuclear power), we have reason to think that this would be more effective.

One might object that these measures are, in certain sense, unprincipled. If the worry is just that these measures aren't going to stop us using our background political beliefs and cultural values to decide how much weight to give to evidence and information we receive, then I would grant the point, but respond that this would be asking too much. But if the worry is that these measures are aimed at better marketing science rather than at winning people over by the force of reasons and evidence, then I would respond that the whole point is to market science in such a way that people can be won over by the force of reasons and evidence.

\section{Acknowledgements}

I would like to thank three anonymous referees for this journal, Jeroen de Ridder, Michael Hannon and audiences in Manchester, Cologne, Glasgow and Bratislava for helpful comments on earlier versions of this paper. Work on this paper was assisted by funding from the ERC Advanced Grant Project “The Emergence of Relativism” (Grant No. 339382). 


\section{Notes}

${ }^{1}$ Because the literature I deal with is US-centric, it makes sense to adopt a US-centric framing of political debate.

${ }^{2}$ As I use the term, 'global warming' refers to increase in global temperature whereas 'climate change' refers to a broader range of phenomena including increase in global temperature but also rising sea levels, extreme weather events, loss of ice at the North and South poles, etc.

${ }^{3}$ I choose Wyoming because the Yale Programme on Climate Change Communication identifies it as the state with the highest rate of climate change denial (see http://climatecommunication.yale.edu/visualizations-data/ycom-us-

2016/ ?est $=$ happening\&type $=$ value\&geo $=$ county $)$.

${ }^{4}$ Anthony Leiserowitz and others, Politics \& Global Warming, May 2017 (Yale University and George Mason University, New Haven, CT: Yale Program on Climate Change Communication, 2017).

${ }^{5}$ Gordon Hodson and Michael Busseri, 'Bright Minds and Dark Attitudes: Lower Cognitive Ability Predicts Greater Prejudice Through Right-Wing Ideology and Low Intergroup Contact', Psychological Science, 23, 2 (2012): 187-95; Satoshi Kanazawa, 'Why Liberals and Atheists Are More Intelligent', Social Psychology Quarterly, 73, 1 (2010): 33-57.

${ }^{6}$ John T. Jost and others, 'Political Conservatism as Motivated Social Cognition', Psychological Bulletin, 129, 3 (2003): 339-75; Erik C. Nisbet and others, 'Attitude Change in Competitive Framing Environments? Open-/Closed-Mindedness, Framing Effects, and Climate Change', Journal of Communication, 63 (2013): 766-85.

${ }^{7}$ Dan Kahan, 'The Politically Motivated Reasoning Paradigm, Part 1: What Politically Motivated Reasoning Is and How to Measure It' in R. Scott and S. Kosslyn (eds.) Emerging Trends in the Social and Behavioral Sciences (John Wiley and Sons, 2016), pp. 1-16; Dan Kahan, David Hoffman, and others, "Ideology" or "Situation Sense"? An Experimental Investigation of Motivated Reasoning and Professional Judgment', University of Pennsylvania Law Review, 164, 349 (2016): 349-438; Dan Kahan, 'Making Climate-Science Communication Evidence-Based--All the Way Down' in M. Boykoff and D. Crow (eds.) Culture, Politics and Climate Change (New York: Routledge, 2014), pp. 
203-20; Dan Kahan, Hank Jenkins-Smith, and Donald Braman, 'Cultural Cognition of Scientific Consensus', Journal of Risk Research, 14,2 (2011): 147-74.

${ }^{8}$ Daniel C. Molden and E. Tory Higgins, 'Motivated Thinking' in K.J. Holyoak and R.G. Morrison (eds.) The Oxford Handbook of Thinking and Reasoning (Oxford: Oxford University Press, 2012), pp. 390-409.

${ }^{9}$ Gifford W. Bradley, 'Self-Serving Biases in the Attribution Process: A Reexamination of the Fact or Fiction Question', Journal of Personality and Social Psychology, 36, 1 (1978): 56-71.

${ }^{10}$ Peter H. Ditto and others, 'Motivated Sensitivity to Preference-Inconsistent Information', Journal of Personality and Social Psychology, 75, 1 (1998): 53-69; Ziva Kunda, 'Motivated Inference: SelfServing Generation and Evaluation of Causal Theories', Journal of Personality and Social Psychology, 53, 4 (1987): 636-47.

${ }^{11}$ Charles G. Lord, Lee Ross, and Mark R. Lepper, 'Biased Assimiliation and Attitude Polarization: The Effects of Prior Theories on Subsequently Considered Evidence', Journal of Personality and Social Psychology, 37, 11 (1979): 2098-2109.

${ }^{12}$ David Dunning and Geoffrey D. Cohen, 'Egocentric Definitions of Traits and Abilities in Social Judgment', Journal of Personality and Social Psychology, 63, 3 (1992): 341-55; David Dunning, Ann Leuenberger, and David A. Sherman, 'A New Look at Motivated Inference: Are Self-Serving Theories of Success a Product of Motivational Forces?', Journal of Personality and Social Psychology, 69, 1 (1995): 58-68; William Klein and Ziva Kunda, 'Motivated Person Perception: Constructing Justifications for Desired Beliefs', Journal of Experimental Social Psychology, 28, 2 (1992): 145-68; Justin Kruger and David Dunning, 'Unskilled and Unaware of It: How Difficulties in Recognizing One's Own Incompetence Leads to Inflated Self-Assessments', Journal of Personality and Social Psychology, 77, 6 (1999): 1121-34; Marc Riess and Jim Taylor, 'Ego-Involvement and Attributions for Success and Failure in a Field Setting', Personality and Social Psychology Bulletin, 10, 4 (1984): 536-43.

${ }^{13}$ John T. Jost, Erin P. Hennes, and Howard Lavine, “Hot” Political Cognition: Its Self-, Group, and System-Serving Purposes' in D.E. Carlston (eds.) The Oxford Handbook of Social Cognition (New York: Oxford University Press, 2013), pp. 851-75; Kahan, 'Making Climate-Science Communication Evidence-Based--All the Way Down'; Kahan, 'The Politically Motivated Reasoning Paradigm, Part 1: What Politically Motivated Reasoning Is and How to Measure It'; 16 
Kahan, Hoffman, and others, “Ideology" or "Situation Sense”? An Experimental Investigation of Motivated Reasoning and Professional Judgment'; Milton Lodge and Charles S. Taber, The Rationalizing Voter (New York: Cambridge University Press, 2013); David P. Redlawsk, 'Hot Cognition or Cool Consideration? Testing the Effects of Motivated Reasoning on Political Decision Making', The Journal of Politics, 64, 4 (2002): 1021-44; Charles S. Taber and Milton Lodge, 'Motivated Skepticism in the Evaluation of Political Beliefs', American Journal of Political Science, 50, 3 (2006): 755-69.

${ }^{14}$ Taber and Lodge, 'Motivated Skepticism in the Evaluation of Political Beliefs', American Journal of Political Science, 50, 3 (2006): 755-69.

${ }^{15}$ Christopher H Achen and Larry Bartels, Democracy for Realists: Why Elections Do Not Produce Responsive Government (Princeton, N.J: Princeton University Press, 2016); Jason Brennan, Against Democracy (Princeton, N.J: Princeton University Press, 2016); Ilya Somin, Democracy and Political Ignorance: Why Smaller Government Is Smarter (Palo Alto, CA: Stanford University Press, 2013).

${ }^{16}$ See Kahan, Hank Jenkins-Smith, and Donald Braman, 'Cultural Cognition of Scientific Consensus': $147-74$ for the percentages and further details for this and the following claims.

${ }^{17}$ National Research Council Committee on Analysis of Global Change Assessments, Analysis of Global Change Assessments: Lessons Learned (Washington, D.C.: National Academies Press, 2007).

${ }^{18}$ National Research Council Board on Radioactive Waste Management, Rethinking High-Level Radioactive Waste Disposal: A Position Statement of the Board on Radioactive Waste Management (Washington, D.C.: National Academy Press, 1990).

${ }^{19}$ National Research Council Committee to Improve Research Information and Data on Firearms, Firearms and Violence: A Critical Review (Washington, D.C.: National Academies Press, 2004).

${ }^{20}$ A quick word on terminology: I will sometimes talk about cultural cognition as a 'belief-forming process'. Cultural cognition is a belief-forming process in much the same sense in which wishful thinking is a belief-forming process. That is, it is just a form of thinking, but it is worthy of particular attention because of the goals and motivations that drive it.

${ }^{21}$ John G. Bullock, Alan S. Gerber, and Seth J. Hill, 'Partisan Bias in Factual Beliefs about Politics', Quarterly Journal of Political Science, 10 (2015): 519-78; Markus Prior, Gaurav Sood, and Kabir 
Khanna, 'You Cannot Be Serious: The Impact of Accuracy Incentives on Partisan Bias in Reports of Economic Perceptions', Quarterly Journal of Political Science, 10 (2015): 489-518.

${ }^{22}$ Lauren C. Howe and John A. Krosnick, 'Attitude Strength', Annual Review of Psychology, 68 (2017): $327-51$.

${ }^{23}$ Kahan, Hoffman, and others, “Ideology" or "Situation Sense”? An Experimental Investigation of Motivated Reasoning and Professional Judgment'.

${ }^{24}$ Dan Kahan, Ellen Peters, and others, 'The Polarizing Impact of Science Literacy and Numeracy on Perceived Climate Change Risks', Nature Climate Change, 2 (2012): 732.

${ }^{25}$ For papers on a range of topics see http://www.culturalcognition.net/papers-topical/.

${ }^{26}$ G. A. Cohen, If You're an Egalitarian, How Come You're So Rich? (Cambridge, MA: Harvard University Press, 2001).

${ }^{27}$ Andreas L. Mogensen, 'Contingency Anxiety and the Epistemology of Disagreement', Pacific Philosophical Quarterly, 97, 4 (2016): 590-611; Amia Srinivasan, 'The Archimedean Urge', Philosophical Perspectives, 29, 1 (2015): 325-62; Roger White, 'You Just Believe That Because...', Philosophical Perspectives, 24, 1 (2010): 573-615.

${ }^{28}$ I discuss what 'independent' means here in $\$ 5$.

${ }^{29}$ Katia Vavova, 'Irrelevant Influences', Philosophy and Phenomenological Research, 96, 1 (2018): 134 52 (p. 12).

${ }^{30}$ Kahan, Jenkins-Smith, and Braman, 'Cultural Cognition of Scientific Consensus'.

${ }^{31}$ More generally, we assess expertise in a domain in terms of fit with our beliefs in that domain Erie D. Boorman and others, 'The Behavioral and Neural Mechanisms Underlying the Tracking of Expertise', Neuron, 80, 6 (2013): 1558-71; Ali Faraji-Rad, Bendik M. Samuelsen, and Luk Warlop, 'On the Persuasiveness of Similar Others: The Role of Mentalizing and the Feeling of Certainty', Journal of Consumer Research, 42, 3 (2015): 458-71; Leonhard Schilbach and others, 'To You I Am Listening: Perceived Competence of Advisors Influences Judgment and DecisionMaking Via Recruitment of the Amygdala', Social Neuroscience, 8, 3 (2013): 189-202.. 
${ }^{32}$ Vavova, 'Irrelevant Influences’, p. 145.

${ }^{33}$ For a similar line of thought applied to peer disagreement see David Christensen, 'Disagreement, Question-Begging and Epistemic Self-Criticism', Philosophers' Imprint, 11, 6 (2011): 1-22; David Christensen, 'Epistemology of Disagreement: The Good News', Philosophical Review, 116 (2007): $187-217$.

${ }^{34}$ This is a modified version of a case in Errol Lord, 'From Independence to Conciliationism: An Obituary', Australasian Journal of Philosophy, 92, 2 (2014): 365-77. Lord uses his case to argue against the sort of independence principle proposed by Christensen in the peer disagreement literature (see fn. 33). I am suggesting that a variant of it makes trouble for GIRP.

${ }^{35}$ In effect, I am proposing that a (good) reason to think your belief is mistaken should lead you to revise your confidence when it is an undercutting defeater for your belief. For more on defeaters see John L. Pollock and Joseph Cruz, Contemporary Theories of Knowledge (Lanham, MA: Rowman \& Littlefield, 1999). The thought is that, just as your belief that there is a red table in front of you is undermined by learning you are hallucinating, your belief that (say) there is no safe way of disposing of nuclear waste is undermined by learning that it was produced by a belief-forming process (cultural cognition) that isn't reliable.

${ }^{36}$ If you like, add that she also lacks independent reasons for thinking these beliefs are true.

${ }^{37}$ Ditto and others, 'Motivated Sensitivity to Preference-Inconsistent Information'; Dunning, Leuenberger, and Sherman, 'A New Look at Motivated Inference: Are Self-Serving Theories of Success a Product of Motivational Forces?'; Phoebe C. Ellsworth and Lee Ross, 'Public Opinion and Capital Punishment: A Close Examination of the Views of Abolitionists and Retentionists', Crime \& Delinquency, 29, 1 (1983): 116-69; Leon Festinger, Henry Riecken, and Stanley Schachter, When Prophecy Fails (Minneapolis: University of Minnesota Press, 1956); Lee Ross and Mark R. Lepper, 'The Perseverance of Beliefs: Empirical and Normative Considerations' in R.A. Schweder (ed.) New Directions for Methodology of Behavioral Science: Fallible Judgment in Behavioral Research (San Francisco: Jossey-Bass, 1980), pp. 17-36.

${ }^{38}$ I would like to thank an anonymous referee for urging me to consider this objection.

${ }^{39}$ Herbert A. Simon, Models of Bounded Rationality (Cambridge, MA: MIT Press, 1982). 
${ }^{40}$ Claude M. Steele, 'The Psychology of Self-Affirmation: Sustaining the Integrity of the Self' in L. Berkowitz (ed.) Advances in Experimental Social Psychology (New York: Academic Press, 1988), PP. 261-302.

${ }^{41}$ Geoffrey L. Cohen, Joshua Aronson, and Claude M. Steele, 'When Beliefs Yield to Evidence: Reducing Biased Evaluation by Affirming the Self, Personality and Social Psychology Bulletin, 26, 9 (2000): 1151-64; David A. Sherman, Leif D. Nelson, and Claude M. Steele, 'Do Messages about Health Risks Threaten the Self? Increasing the Acceptance of Threatening Health Messages via Self-Affirmation', Personality and Social Psychology Bulletin, 26, 9 (2000): 1046-57.

${ }^{42}$ Kahan, 'Making Climate-Science Communication Evidence-Based--All the Way Down'.

${ }^{43}$ One finds this narrative in both the philosophy of science literature (Philip Kitcher, Science in a Democratic Society (Prometheus Books, 2011)) and the empirical literature (e.g. Jost and others, 'Political Conservatism as Motivated Social Cognition'; Sheldon Ungar, 'Knowledge, Ignorance and the Popular Culture: Climate Change versus the Ozone Hole', Public Understanding of Science, 9, 3 (2000): 297-312.).

${ }^{44}$ Elizabeth Anderson, 'The Epistemology of Democracy', Episteme, 3, 1-2 (2006): 8-22.

${ }^{45}$ Cohen, Aronson, and Steele; Michael D. Jones and Mark K. McBeth, 'A Narrative Policy Framework: Clear Enough to Be Wrong?', Policy Studies Journal, 38, 2 (2010): 329-53; Dan Kahan, Maggie Wittlin, and others, 'The Tragedy of the Risk-Perception Commons: Culture Conflict, Rationality Conflict, and Climate Change', Temple University Legal Studies Research Paper No. 2011-26; Cultural Cognition Project Working Paper No. 89; Yale Law \& Economics Research Paper No. 435; Yale Law School, Public Law Working Paper No. 230, 2011 <Available at SSRN: https://ssrn.com/abstract=1871503>; Kahan, 'Making Climate-Science Communication Evidence-Based--All the Way Down'; Bo MacInnis and others, 'The American Public's Preference for Preparation for the Possible Effects of Global Warming: Impact of Communication Strategies', Climatic Change, 128, 1-2 (2015): 17-33; Marco Verweij and others, 'Clumsy Solutions for a Complex World: The Case of Climate Change', Public Administration, 84,4 (2006): 817-43. 